\title{
Functional equations in paranormed spaces
}

\section{Choonkil Park ${ }^{1}$ and Dong Yun Shin ${ }^{2 *}$}

${ }^{\text {*Correspondence: dyshin@uos.ac.kr }}$ ${ }^{2}$ Department of Mathematics, University of Seoul, Seoul, 130-743, Korea

Full list of author information is available at the end of the article

\begin{abstract}
In this paper, we prove the Hyers-Ulam stability of various functional equations in paranormed spaces.
\end{abstract}

MSC: Primary 35A17; 39B52; 39B72

Keywords: Hyers-Ulam stability; paranormed space; functional equation

\section{Introduction and preliminaries}

The concept of statistical convergence for sequences of real numbers was introduced by Fast [1] and Steinhaus [2] independently, and since then several generalizations and applications of this notion have been investigated by various authors (see [3-7]). This notion was defined in normed spaces by Kolk [8].

We recall some basic facts concerning Fréchet spaces.

Definition 1.1 ([9]) Let $X$ be a vector space. A paranorm $P: X \rightarrow[0, \infty)$ is a function on $X$ such that

(1) $P(0)=0$;

(2) $P(-x)=P(x)$;

(3) $P(x+y) \leq P(x)+P(y)$ (triangle inequality);

(4) If $\left\{t_{n}\right\}$ is a sequence of scalars with $t_{n} \rightarrow t$ and $\left\{x_{n}\right\} \subset X$ with $P\left(x_{n}-x\right) \rightarrow 0$, then $P\left(t_{n} x_{n}-t x\right) \rightarrow 0$ (continuity of multiplication).

The pair $(X, P)$ is called a paranormed space if $P$ is a paranorm on $X$.

The paranorm is called total if, in addition, we have

(5) $P(x)=0$ implies $x=0$.

A Fréchet space is a total and complete paranormed space.

The stability problem of functional equations originated from a question of Ulam [10] concerning the stability of group homomorphisms. Hyers [11] gave a first affirmative partial answer to the question of Ulam for Banach spaces. Hyers' Theorem was generalized by Aoki [12] for additive mappings and by Th. M. Rassias [13] for linear mappings by considering an unbounded Cauchy difference. A generalization of the Th. M. Rassias' theorem was obtained by Găvruta [14] by replacing the unbounded Cauchy difference by a general control function in the spirit of Th. M. Rassias' approach.

In 1990 during the 27th International Symposium on Functional Equations, Th. M. Rassias [15] asked the question whether such a theorem can also be proved for $p \geq 1$. In 1991 Gajda [16], following the same approach as in Th. M. Rassias [13], gave an affirmative solution to this question for $p>1$. It was shown by Gajda [16], as well as by Th. M. Rassias 
and Šemrl [17] that one cannot prove a Th. M. Rassias' type theorem when $p=1$ (cf. the books of P. Czerwik [18], D. H. Hyers, G. Isac and Th. M. Rassias [19]).

In 1982 J. M. Rassias [20] followed the innovative approach of the Th. M. Rassias' theorem [13] in which he replaced the factor $\|x\|^{p}+\|y\|^{p}$ by $\|x\|^{p} \cdot\|y\|^{q}$ for $p, q \in \mathbb{R}$ with $p+q \neq 1$. Găvruta [14] provided a further generalization of Th. M. Rassias' theorem.

The functional equation

$$
f(x+y)+f(x-y)=2 f(x)+2 f(y)
$$

is called a quadratic functional equation. In particular, every solution of the quadratic functional equation is said to be a quadratic mapping. A Hyers-Ulam stability problem for the quadratic functional equation was proved by Skof [21] for mappings $f: X \rightarrow Y$, where $X$ is a normed space and $Y$ is a Banach space. Cholewa [22] noticed that the theorem of Skof is still true if the relevant domain $X$ is replaced by an Abelian group. Czerwik [23] proved the Hyers-Ulam stability of the quadratic functional equation. The stability problems of several functional equations have been extensively investigated by a number of authors and there are many interesting results concerning this problem (see [24-33]).

In [34], Jun and Kim considered the following cubic functional equation

$$
f(2 x+y)+f(2 x-y)=2 f(x+y)+2 f(x-y)+12 f(x) .
$$

It is easy to show that the function $f(x)=x^{3}$ satisfies the functional equation (1.1), which is called a cubic functional equation and every solution of the cubic functional equation is said to be a cubic mapping.

In [35], Lee et al. considered the following quartic functional equation

$$
f(2 x+y)+f(2 x-y)=4 f(x+y)+4 f(x-y)+24 f(x)-6 f(y) .
$$

It is easy to show that the function $f(x)=x^{4}$ satisfies the functional equation (1.2), which is called a quartic functional equation, and every solution of the quartic functional equation is said to be a quartic mapping.

Throughout this paper, assume that $(X, P)$ is a Fréchet space and that $(Y,\|\cdot\|)$ is a Banach space.

In this paper, we prove the Hyers-Ulam stability of the Cauchy additive functional equation, the quadratic functional equation, the cubic functional equation (1.1) and the quartic functional equation (1.2) in paranormed spaces.

\section{Hyers-Ulam stability of the Cauchy additive functional equation}

In this section, we prove the Hyers-Ulam stability of the Cauchy additive functional equation in paranormed spaces.

Note that $P(2 x) \leq 2 P(x)$ for all $x \in Y$.

Theorem 2.1 Let $r, \theta$ be positive real numbers with $r>1$, and let $f: Y \rightarrow X$ be an odd mapping such that

$$
P(f(x+y)-f(x)-f(y)) \leq \theta\left(\|x\|^{r}+\|y\|^{r}\right)
$$


for all $x, y \in Y$. Then there exists a unique Cauchy additive mapping $A: Y \rightarrow X$ such that

$$
P(f(x)-A(x)) \leq \frac{2 \theta}{2^{r}-2}\|x\|^{r}
$$

for all $x \in Y$.

Proof Letting $y=x$ in (2.1), we get

$$
P(f(2 x)-2 f(x)) \leq 2 \theta\|x\|^{r}
$$

for all $x \in Y$. So

$$
P\left(f(x)-2 f\left(\frac{x}{2}\right)\right) \leq \frac{2}{2^{r}} \theta\|x\|^{r}
$$

for all $x \in Y$. Hence

$$
\begin{aligned}
P\left(2^{l} f\left(\frac{x}{2^{l}}\right)-2^{m} f\left(\frac{x}{2^{m}}\right)\right) & \leq \sum_{j=l}^{m-1} P\left(2^{j} f\left(\frac{x}{2^{j}}\right)-2^{j+1} f\left(\frac{x}{2^{j+1}}\right)\right) \\
& \leq \frac{2}{2^{r}} \sum_{j=l}^{m-1} \frac{2^{j}}{2^{r j}} \theta\|x\|^{r}
\end{aligned}
$$

for all nonnegative integers $m$ and $l$ with $m>l$ and all $x \in Y$. It follows from (2.3) that the sequence $\left\{2^{n} f\left(\frac{x}{2^{n}}\right)\right\}$ is a Cauchy sequence for all $x \in Y$. Since $X$ is complete, the sequence $\left\{2^{n} f\left(\frac{x}{2^{n}}\right)\right\}$ converges. So one can define the mapping $A: Y \rightarrow X$ by

$$
A(x):=\lim _{n \rightarrow \infty} 2^{n} f\left(\frac{x}{2^{n}}\right)
$$

for all $x \in Y$. Moreover, letting $l=0$ and passing the limit $m \rightarrow \infty$ in (2.3), we get (2.2).

It follows from (2.1) that

$$
\begin{aligned}
P(A(x+y)-A(x)-A(y)) & =\lim _{n \rightarrow \infty} P\left(2^{n}\left(f\left(\frac{x+y}{2^{n}}\right)-f\left(\frac{x}{2^{n}}\right)-f\left(\frac{y}{2^{n}}\right)\right)\right) \\
& \leq \lim _{n \rightarrow \infty} 2^{n} P\left(f\left(\frac{x+y}{2^{n}}\right)-f\left(\frac{x}{2^{n}}\right)-f\left(\frac{y}{2^{n}}\right)\right) \\
& \leq \lim _{n \rightarrow \infty} \frac{2^{n} \theta}{2^{n r}}\left(\|x\|^{r}+\|y\|^{r}\right)=0
\end{aligned}
$$

for all $x, y \in Y$. Hence $A(x+y)=A(x)+A(y)$ for all $x, y \in Y$ and so the mapping $A: Y \rightarrow X$ is Cauchy additive.

Now, let $T: Y \rightarrow X$ be another Cauchy additive mapping satisfying (2.2). Then we have

$$
\begin{aligned}
P(A(x)-T(x)) & =P\left(2^{n}\left(A\left(\frac{x}{2^{n}}\right)-T\left(\frac{x}{2^{n}}\right)\right)\right) \\
& \leq 2^{n} P\left(A\left(\frac{x}{2^{n}}\right)-T\left(\frac{x}{2^{n}}\right)\right)
\end{aligned}
$$




$$
\begin{aligned}
& \leq 2^{n}\left(P\left(A\left(\frac{x}{2^{n}}\right)-f\left(\frac{x}{2^{n}}\right)\right)+P\left(T\left(\frac{x}{2^{n}}\right)-f\left(\frac{x}{2^{n}}\right)\right)\right) \\
& \leq \frac{4 \cdot 2^{n}}{\left(2^{r}-2\right) 2^{n r}} \theta\|x\|^{r},
\end{aligned}
$$

which tends to zero as $n \rightarrow \infty$ for all $x \in Y$. So we can conclude that $A(x)=T(x)$ for all $x \in Y$. This proves the uniqueness of $A$. Thus the mapping $A: Y \rightarrow X$ is a unique Cauchy additive mapping satisfying (2.2).

Theorem 2.2 Let $r$ be a positive real number with $r<1$, and let $f: X \rightarrow Y$ be an odd mapping such that

$$
\|f(x+y)-f(x)-f(y)\| \leq P(x)^{r}+P(y)^{r}
$$

for all $x, y \in X$. Then there exists a unique Cauchy additive mapping $A: X \rightarrow Y$ such that

$$
\|f(x)-A(x)\| \leq \frac{2}{2-2^{r}} P(x)^{r}
$$

for all $x \in X$.

Proof Letting $y=x$ in (2.4), we get

$$
\|2 f(x)-f(2 x)\| \leq 2 P(x)^{r}
$$

and so

$$
\left\|f(x)-\frac{1}{2} f(2 x)\right\| \leq P(x)^{r}
$$

for all $x \in X$. Hence

$$
\begin{aligned}
\left\|\frac{1}{2^{l}} f\left(2^{l} x\right)-\frac{1}{2^{m}} f\left(2^{m} x\right)\right\| & \leq \sum_{j=l}^{m-1}\left\|\frac{1}{2^{j}} f\left(2^{j} x\right)-\frac{1}{2^{j+1}} f\left(2^{j+1} x\right)\right\| \\
& \leq \sum_{j=l}^{m-1} \frac{2^{r j}}{2^{j}} P(x)^{r}
\end{aligned}
$$

for all nonnegative integers $m$ and $l$ with $m>l$ and all $x \in X$. It follows from (2.6) that the sequence $\left\{\frac{1}{2^{n}} f\left(2^{n} x\right)\right\}$ is a Cauchy sequence for all $x \in X$. Since $Y$ is complete, the sequence $\left\{\frac{1}{2^{n}} f\left(2^{n} x\right)\right\}$ converges. So one can define the mapping $A: X \rightarrow Y$ by

$$
A(x):=\lim _{n \rightarrow \infty} \frac{1}{2^{n}} f\left(2^{n} x\right)
$$

for all $x \in X$. Moreover, letting $l=0$ and passing the limit $m \rightarrow \infty$ in (2.6), we get (2.5).

It follows from (2.4) that

$$
\begin{aligned}
\|A(x+y)-A(x)-A(y)\| & =\lim _{n \rightarrow \infty} \frac{1}{2^{n}}\left\|f\left(2^{n}(x+y)\right)-f\left(2^{n} x\right)-f\left(2^{n} y\right)\right\| \\
& \leq \lim _{n \rightarrow \infty} \frac{2^{n r}}{2^{n}}\left(P(x)^{r}+P(y)^{r}\right)=0
\end{aligned}
$$


for all $x, y \in X$. Thus $A(x+y)=A(x)+A(y)$ for all $x, y \in X$ and so the mapping $A: X \rightarrow Y$ is Cauchy additive.

Now, let $T: X \rightarrow Y$ be another Cauchy additive mapping satisfying (2.5). Then we have

$$
\begin{aligned}
\|A(x)-T(x)\| & =\frac{1}{2^{n}}\left\|A\left(2^{n} x\right)-T\left(2^{n} x\right)\right\| \\
& \leq \frac{1}{2^{n}}\left(\left\|A\left(2^{n} x\right)-f\left(2^{n} x\right)\right\|+\left\|T\left(2^{n} x\right)-f\left(2^{n} x\right)\right\|\right) \\
& \leq \frac{4 \cdot 2^{n r}}{\left(2-2^{r}\right) 2^{n}} P(x)^{r},
\end{aligned}
$$

which tends to zero as $n \rightarrow \infty$ for all $x \in X$. So we can conclude that $A(x)=T(x)$ for all $x \in X$. This proves the uniqueness of $A$. Thus the mapping $A: X \rightarrow Y$ is a unique Cauchy additive mapping satisfying (2.5).

\section{Hyers-Ulam stability of the quadratic functional equation}

In this section, we prove the Hyers-Ulam stability of the quadratic functional equation in paranormed spaces.

Note that $P(2 x) \leq 2 P(x)$ for all $x \in Y$.

Theorem 3.1 Let $r, \theta$ be positive real numbers with $r>2$, and let $f: Y \rightarrow X$ be a mapping satisfying $f(0)=0$ and

$$
P(f(x+y)+f(x-y)-2 f(x)-2 f(y)) \leq \theta\left(\|x\|^{r}+\|y\|^{r}\right)
$$

for all $x, y \in Y$. Then there exists a unique quadratic mapping $Q_{2}: Y \rightarrow X$ such that

$$
P\left(f(x)-Q_{2}(x)\right) \leq \frac{2 \theta}{2^{r}-4}\|x\|^{r}
$$

for all $x \in Y$.

Proof Letting $y=x$ in (3.1), we get

$$
P(f(2 x)-4 f(x)) \leq 2 \theta\|x\|^{r}
$$

for all $x \in Y$. So

$$
P\left(f(x)-4 f\left(\frac{x}{2}\right)\right) \leq \frac{2}{2^{r}} \theta\|x\|^{r}
$$

for all $x \in Y$. Hence

$$
\begin{aligned}
P\left(4^{l} f\left(\frac{x}{2^{l}}\right)-4^{m} f\left(\frac{x}{2^{m}}\right)\right) & \leq \sum_{j=l}^{m-1} P\left(4^{j} f\left(\frac{x}{2^{j}}\right)-4^{j+1} f\left(\frac{x}{2^{j+1}}\right)\right) \\
& \leq \frac{2}{2^{r}} \sum_{j=l}^{m-1} \frac{4^{j}}{2^{r j}} \theta\|x\|^{r}
\end{aligned}
$$


for all nonnegative integers $m$ and $l$ with $m>l$ and all $x \in Y$. It follows from (3.3) that the sequence $\left\{4^{n} f\left(\frac{x}{2^{n}}\right)\right\}$ is a Cauchy sequence for all $x \in Y$. Since $X$ is complete, the sequence $\left\{4^{n} f\left(\frac{x}{2^{n}}\right)\right\}$ converges. So one can define the mapping $Q_{2}: Y \rightarrow X$ by

$$
Q_{2}(x):=\lim _{n \rightarrow \infty} 4^{n} f\left(\frac{x}{2^{n}}\right)
$$

for all $x \in Y$. Moreover, letting $l=0$ and passing the limit $m \rightarrow \infty$ in (3.3), we get (3.2).

It follows from (3.1) that

$$
\begin{aligned}
& P\left(Q_{2}(x+y)+Q_{2}(x-y)-2 Q_{2}(x)-2 Q_{2}(y)\right) \\
& \quad=\lim _{n \rightarrow \infty} P\left(4^{n}\left(f\left(\frac{x+y}{2^{n}}\right)+f\left(\frac{x-y}{2^{n}}\right)-2 f\left(\frac{x}{2^{n}}\right)-2 f\left(\frac{y}{2^{n}}\right)\right)\right) \\
& \quad \leq \lim _{n \rightarrow \infty} 4^{n} P\left(f\left(\frac{x+y}{2^{n}}\right)+f\left(\frac{x-y}{2^{n}}\right)-2 f\left(\frac{x}{2^{n}}\right)-2 f\left(\frac{y}{2^{n}}\right)\right) \\
& \quad \leq \lim _{n \rightarrow \infty} \frac{4^{n} \theta}{2^{n r}}\left(\|x\|^{r}+\|y\|^{r}\right)=0
\end{aligned}
$$

for all $x, y \in Y$. Hence $Q_{2}(x+y)+Q_{2}(x-y)=2 Q_{2}(x)+2 Q_{2}(y)$ for all $x, y \in Y$ and so the mapping $Q_{2}: Y \rightarrow X$ is quadratic.

Now, let $T: Y \rightarrow X$ be another quadratic mapping satisfying (3.2). Then we have

$$
\begin{aligned}
P\left(Q_{2}(x)-T(x)\right) & =P\left(4^{n}\left(Q_{2}\left(\frac{x}{2^{n}}\right)-T\left(\frac{x}{2^{n}}\right)\right)\right) \\
& \leq 4^{n} P\left(Q_{2}\left(\frac{x}{2^{n}}\right)-T\left(\frac{x}{2^{n}}\right)\right) \\
& \leq 4^{n}\left(P\left(Q_{2}\left(\frac{x}{2^{n}}\right)-f\left(\frac{x}{2^{n}}\right)\right)+P\left(T\left(\frac{x}{2^{n}}\right)-f\left(\frac{x}{2^{n}}\right)\right)\right) \\
& \leq \frac{4 \cdot 4^{n}}{\left(2^{r}-4\right) 2^{n r}} \theta\|x\|^{r},
\end{aligned}
$$

which tends to zero as $n \rightarrow \infty$ for all $x \in Y$. So we can conclude that $Q_{2}(x)=T(x)$ for all $x \in Y$. This proves the uniqueness of $Q_{2}$. Thus the mapping $Q_{2}: Y \rightarrow X$ is a unique quadratic mapping satisfying (3.2).

Theorem 3.2 Let $r$ be a positive real number with $r<2$, and let $f: X \rightarrow Y$ be a mapping satisfying $f(0)=0$ and

$$
\|f(x+y)+f(x-y)-2 f(x)-2 f(y)\| \leq P(x)^{r}+P(y)^{r}
$$

for all $x, y \in X$. Then there exists a unique quadratic mapping $Q_{2}: X \rightarrow Y$ such that

$$
\left\|f(x)-Q_{2}(x)\right\| \leq \frac{2}{4-2^{r}} P(x)^{r}
$$

for all $x \in X$. 
Proof Letting $y=x$ in (3.4), we get

$$
\|4 f(x)-f(2 x)\| \leq 2 P(x)^{r}
$$

and so

$$
\left\|f(x)-\frac{1}{4} f(2 x)\right\| \leq \frac{1}{2} P(x)^{r}
$$

for all $x \in X$. Hence

$$
\begin{aligned}
\left\|\frac{1}{4^{l}} f\left(2^{l} x\right)-\frac{1}{4^{m}} f\left(2^{m} x\right)\right\| & \leq \sum_{j=l}^{m-1}\left\|\frac{1}{4^{j}} f\left(2^{j} x\right)-\frac{1}{4^{j+1}} f\left(2^{j+1} x\right)\right\| \\
& \leq \frac{1}{2} \sum_{j=l}^{m-1} \frac{2^{r j}}{4^{j}} P(x)^{r}
\end{aligned}
$$

for all nonnegative integers $m$ and $l$ with $m>l$ and all $x \in X$. It follows from (3.6) that the sequence $\left\{\frac{1}{4^{n}} f\left(2^{n} x\right)\right\}$ is a Cauchy sequence for all $x \in X$. Since $Y$ is complete, the sequence $\left\{\frac{1}{4^{n}} f\left(2^{n} x\right)\right\}$ converges. So one can define the mapping $Q_{2}: X \rightarrow Y$ by

$$
Q_{2}(x):=\lim _{n \rightarrow \infty} \frac{1}{4^{n}} f\left(2^{n} x\right)
$$

for all $x \in X$. Moreover, letting $l=0$ and passing the limit $m \rightarrow \infty$ in (3.6), we get (3.5).

It follows from (3.4) that

$$
\begin{aligned}
& \left\|Q_{2}(x+y)+Q_{2}(x-y)-2 Q_{2}(x)-2 Q_{2}(y)\right\| \\
& =\lim _{n \rightarrow \infty} \frac{1}{4^{n}}\left\|f\left(2^{n}(x+y)\right)+f\left(2^{n}(x-y)\right)-2 f\left(2^{n} x\right)-2 f\left(2^{n} y\right)\right\| \\
& \leq \lim _{n \rightarrow \infty} \frac{2^{n r}}{4^{n}}\left(P(x)^{r}+P(y)^{r}\right)=0
\end{aligned}
$$

for all $x, y \in X$. Thus $Q_{2}(x+y)+Q_{2}(x-y)=2 Q_{2}(x)+2 Q_{2}(y)$ for all $x, y \in X$ and so the mapping $Q_{2}: X \rightarrow Y$ is quadratic.

Now, let $T: X \rightarrow Y$ be another quadratic mapping satisfying (3.5). Then we have

$$
\begin{aligned}
\left\|Q_{2}(x)-T(x)\right\| & =\frac{1}{4^{n}}\left\|Q_{2}\left(2^{n} x\right)-T\left(2^{n} x\right)\right\| \\
& \leq \frac{1}{4^{n}}\left(\left\|Q_{2}\left(2^{n} x\right)-f\left(2^{n} x\right)\right\|+\left\|T\left(2^{n} x\right)-f\left(2^{n} x\right)\right\|\right) \\
& \leq \frac{4 \cdot 2^{n r}}{\left(4-2^{r}\right) 4^{n}} P(x)^{r},
\end{aligned}
$$

which tends to zero as $n \rightarrow \infty$ for all $x \in X$. So we can conclude that $Q_{2}(x)=T(x)$ for all $x \in X$. This proves the uniqueness of $Q_{2}$. Thus the mapping $Q_{2}: X \rightarrow Y$ is a unique quadratic mapping satisfying (3.5). 


\section{Hyers-Ulam stability of the cubic functional equation}

In this section, we prove the Hyers-Ulam stability of the cubic functional equation in paranormed spaces.

Note that $P(2 x) \leq 2 P(x)$ for all $x \in Y$.

Theorem 4.1 Let $r, \theta$ be positive real numbers with $r>3$, and let $f: Y \rightarrow X$ be a mapping such that

$$
P\left(\frac{1}{2} f(2 x+y)+\frac{1}{2} f(2 x-y)-f(x+y)-f(x-y)-6 f(x)\right) \leq \theta\left(\|x\|^{r}+\|y\|^{r}\right)
$$

for all $x, y \in Y$. Then there exists a unique cubic mapping $C: Y \rightarrow X$ such that

$$
P(f(x)-C(x)) \leq \frac{\theta}{2^{r}-8}\|x\|^{r}
$$

for all $x \in Y$.

Proof Letting $y=0$ in (4.1), we get

$$
P(f(2 x)-8 f(x)) \leq \theta\|x\|^{r}
$$

for all $x \in Y$. So

$$
P\left(f(x)-8 f\left(\frac{x}{2}\right)\right) \leq \frac{1}{2^{r}} \theta\|x\|^{r}
$$

for all $x \in Y$. Hence

$$
\begin{aligned}
P\left(8^{l} f\left(\frac{x}{2^{l}}\right)-8^{m} f\left(\frac{x}{2^{m}}\right)\right) & \leq \sum_{j=l}^{m-1} P\left(8^{j} f\left(\frac{x}{2^{j}}\right)-8^{j+1} f\left(\frac{x}{2^{j+1}}\right)\right) \\
& \leq \frac{1}{2^{r}} \sum_{j=l}^{m-1} \frac{8^{j}}{2^{r j}} \theta\|x\|^{r}
\end{aligned}
$$

for all nonnegative integers $m$ and $l$ with $m>l$ and all $x \in Y$. It follows from (4.3) that the sequence $\left\{8^{n} f\left(\frac{x}{2^{n}}\right)\right\}$ is a Cauchy sequence for all $x \in Y$. Since $X$ is complete, the sequence $\left\{8^{n} f\left(\frac{x}{2^{n}}\right)\right\}$ converges. So one can define the mapping $C: Y \rightarrow X$ by

$$
C(x):=\lim _{n \rightarrow \infty} 8^{n} f\left(\frac{x}{2^{n}}\right)
$$

for all $x \in Y$. Moreover, letting $l=0$ and passing the limit $m \rightarrow \infty$ in (4.3), we get (4.2).

It follows from (4.1) that

$$
\begin{aligned}
P & \left(\frac{1}{2} C(2 x+y)+\frac{1}{2} C(2 x-y)-C(x+y)-C(x-y)-6 C(x)\right) \\
\quad & \lim _{n \rightarrow \infty} P\left(8^{n}\left(\frac{1}{2} f\left(\frac{2 x+y}{2^{n}}\right)+\frac{1}{2} f\left(\frac{2 x-y}{2^{n}}\right)-f\left(\frac{x+y}{2^{n}}\right)-f\left(\frac{x-y}{2^{n}}\right)-6 f\left(\frac{x}{2^{n}}\right)\right)\right)
\end{aligned}
$$




$$
\begin{aligned}
& \leq \lim _{n \rightarrow \infty} 8^{n} P\left(\frac{1}{2} f\left(\frac{2 x+y}{2^{n}}\right)+\frac{1}{2} f\left(\frac{2 x-y}{2^{n}}\right)-f\left(\frac{x+y}{2^{n}}\right)-f\left(\frac{x-y}{2^{n}}\right)-6 f\left(\frac{x}{2^{n}}\right)\right) \\
& \leq \lim _{n \rightarrow \infty} \frac{8^{n} \theta}{2^{n r}}\left(\|x\|^{r}+\|y\|^{r}\right)=0
\end{aligned}
$$

for all $x, y \in Y$. Hence

$$
\frac{1}{2} C(2 x+y)+\frac{1}{2} C(2 x-y)=C(x+y)+C(x-y)+6 C(x)
$$

for all $x, y \in Y$ and so the mapping $C: Y \rightarrow X$ is cubic.

Now, let $T: Y \rightarrow X$ be another cubic mapping satisfying (4.2). Then we have

$$
\begin{aligned}
P(C(x)-T(x)) & =P\left(8^{n}\left(C\left(\frac{x}{2^{n}}\right)-T\left(\frac{x}{2^{n}}\right)\right)\right) \\
& \leq 8^{n} P\left(C\left(\frac{x}{2^{n}}\right)-T\left(\frac{x}{2^{n}}\right)\right) \\
& \leq 8^{n}\left(P\left(C\left(\frac{x}{2^{n}}\right)-f\left(\frac{x}{2^{n}}\right)\right)+P\left(T\left(\frac{x}{2^{n}}\right)-f\left(\frac{x}{2^{n}}\right)\right)\right) \\
& \leq \frac{2 \cdot 8^{n}}{\left(2^{r}-8\right) 2^{n r}} \theta\|x\|^{r},
\end{aligned}
$$

which tends to zero as $n \rightarrow \infty$ for all $x \in Y$. So we can conclude that $C(x)=T(x)$ for all $x \in Y$. This proves the uniqueness of $C$. Thus the mapping $C: Y \rightarrow X$ is a unique cubic mapping satisfying (4.2).

Theorem 4.2 Let $r$ be a positive real number with $r<3$, and let $f: X \rightarrow Y$ be a mapping such that

$$
\left\|\frac{1}{2} f(2 x+y)+\frac{1}{2} f(2 x-y)-f(x+y)-f(x-y)-6 f(x)\right\| \leq P(x)^{r}+P(y)^{r}
$$

for all $x, y \in X$. Then there exists a unique cubic mapping $C: X \rightarrow Y$ such that

$$
\|f(x)-C(x)\| \leq \frac{1}{8-2^{r}} P(x)^{r}
$$

for all $x \in X$.

Proof Letting $y=0$ in (4.4), we get

$$
\|8 f(x)-f(2 x)\| \leq P(x)^{r}
$$

and so

$$
\left\|f(x)-\frac{1}{8} f(2 x)\right\| \leq \frac{1}{8} P(x)^{r}
$$

for all $x \in X$. Hence

$$
\left\|\frac{1}{8^{8}} f\left(2^{l} x\right)-\frac{1}{8^{m}} f\left(2^{m} x\right)\right\| \leq \sum_{j=l}^{m-1}\left\|\frac{1}{8^{j}} f\left(2^{j} x\right)-\frac{1}{8^{j+1}} f\left(2^{j+1} x\right)\right\| \leq \frac{1}{8} \sum_{j=l}^{m-1} \frac{2^{r j}}{8^{j}} P(x)^{r}
$$


for all nonnegative integers $m$ and $l$ with $m>l$ and all $x \in X$. It follows from (4.6) that the sequence $\left\{\frac{1}{8^{n}} f\left(2^{n} x\right)\right\}$ is a Cauchy sequence for all $x \in X$. Since $Y$ is complete, the sequence $\left\{\frac{1}{8^{n}} f\left(2^{n} x\right)\right\}$ converges. So one can define the mapping $C: X \rightarrow Y$ by

$$
C(x):=\lim _{n \rightarrow \infty} \frac{1}{8^{n}} f\left(2^{n} x\right)
$$

for all $x \in X$. Moreover, letting $l=0$ and passing the limit $m \rightarrow \infty$ in (4.6), we get (4.5).

It follows from (4.4) that

$$
\begin{aligned}
\left\|\frac{1}{2} C(2 x+y)+\frac{1}{2} C(2 x-y)-C(x+y)-C(x-y)-6 C(x)\right\| \\
=\lim _{n \rightarrow \infty} \frac{1}{8^{n}} \| \frac{1}{2} f\left(2^{n}(2 x+y)\right)+\frac{1}{2} f\left(2^{n}(2 x-y)\right) \\
\quad-f\left(2^{n}(x+y)\right)-f\left(2^{n}(x-y)\right)-6 f\left(2^{n} x\right) \| \\
\leq \lim _{n \rightarrow \infty} \frac{2^{n r}}{8^{n}}\left(P(x)^{r}+P(y)^{r}\right)=0
\end{aligned}
$$

for all $x, y \in X$. Thus

$$
\frac{1}{2} C(2 x+y)+\frac{1}{2} C(2 x-y)=C(x+y)+C(x-y)+6 C(x)
$$

for all $x, y \in X$ and so the mapping $C: X \rightarrow Y$ is cubic.

Now, let $T: X \rightarrow Y$ be another cubic mapping satisfying (4.5). Then we have

$$
\begin{aligned}
\|C(x)-T(x)\| & =\frac{1}{8^{n}}\left\|C\left(2^{n} x\right)-T\left(2^{n} x\right)\right\| \\
& \leq \frac{1}{8^{n}}\left(\left\|C\left(2^{n} x\right)-f\left(2^{n} x\right)\right\|+\left\|T\left(2^{n} x\right)-f\left(2^{n} x\right)\right\|\right) \\
& \leq \frac{2 \cdot 2^{n r}}{\left(8-2^{r}\right) 8^{n}} P(x)^{r},
\end{aligned}
$$

which tends to zero as $n \rightarrow \infty$ for all $x \in X$. So we can conclude that $C(x)=T(x)$ for all $x \in X$. This proves the uniqueness of $C$. Thus the mapping $C: X \rightarrow Y$ is a unique cubic mapping satisfying (4.5).

\section{Hyers-Ulam stability of the quartic functional equation}

In this section, we prove the Hyers-Ulam stability of the quartic functional equation in paranormed spaces.

Note that $P(2 x) \leq 2 P(x)$ for all $x \in Y$.

Theorem 5.1 Let $r, \theta$ be positive real numbers with $r>4$, and let $f: Y \rightarrow X$ be a mapping satisfying $f(0)=0$ and

$$
\begin{aligned}
& P\left(\frac{1}{2} f(2 x+y)+\frac{1}{2} f(2 x-y)-2 f(x+y)-2 f(x-y)-12 f(x)+3 f(y)\right) \\
& \quad \leq \theta\left(\|x\|^{r}+\|y\|^{r}\right)
\end{aligned}
$$


for all $x, y \in Y$. Then there exists a unique quartic mapping $Q_{4}: Y \rightarrow X$ such that

$$
P\left(f(x)-Q_{4}(x)\right) \leq \frac{\theta}{2^{r}-16}\|x\|^{r}
$$

for all $x \in Y$.

Proof Letting $y=0$ in (4.1), we get

$$
P(f(2 x)-16 f(x)) \leq \theta\|x\|^{r}
$$

for all $x \in Y$. So

$$
P\left(f(x)-16 f\left(\frac{x}{2}\right)\right) \leq \frac{1}{2^{r}} \theta\|x\|^{r}
$$

for all $x \in Y$. Hence

$$
\begin{aligned}
& P\left(16^{l} f\left(\frac{x}{2^{l}}\right)-16^{m} f\left(\frac{x}{2^{m}}\right)\right) \\
& \leq \sum_{j=l}^{m-1} P\left(16^{j} f\left(\frac{x}{2^{j}}\right)-16^{j+1} f\left(\frac{x}{2^{j+1}}\right)\right) \\
& \leq \frac{1}{2^{r}} \sum_{j=l}^{m-1} \frac{16^{j}}{2^{r j}} \theta\|x\|^{r}
\end{aligned}
$$

for all nonnegative integers $m$ and $l$ with $m>l$ and all $x \in Y$. It follows from (5.3) that the sequence $\left\{16^{n} f\left(\frac{x}{2^{n}}\right)\right\}$ is a Cauchy sequence for all $x \in Y$. Since $X$ is complete, the sequence $\left\{16^{n} f\left(\frac{x}{2^{n}}\right)\right\}$ converges. So one can define the mapping $Q_{4}: Y \rightarrow X$ by

$$
Q_{4}(x):=\lim _{n \rightarrow \infty} 16^{n} f\left(\frac{x}{2^{n}}\right)
$$

for all $x \in Y$. Moreover, letting $l=0$ and passing the limit $m \rightarrow \infty$ in (5.3), we get (5.2).

It follows from (5.1) that

$$
\begin{aligned}
P( & \left.\frac{1}{2} Q_{4}(2 x+y)+\frac{1}{2} Q_{4}(2 x-y)-2 Q_{4}(x+y)-2 Q_{4}(x-y)-12 Q_{4}(x)+3 Q_{4}(y)\right) \\
= & \lim _{n \rightarrow \infty} P\left(1 6 ^ { n } \left(\frac{1}{2} f\left(\frac{2 x+y}{2^{n}}\right)+\frac{1}{2} f\left(\frac{2 x-y}{2^{n}}\right)-2 f\left(\frac{x+y}{2^{n}}\right)\right.\right. \\
& \left.\left.-2 f\left(\frac{x-y}{2^{n}}\right)-12 f\left(\frac{x}{2^{n}}\right)+3 f\left(\frac{y}{2^{n}}\right)\right)\right) \\
\leq & \lim _{n \rightarrow \infty} 16^{n} P\left(\frac{1}{2} f\left(\frac{2 x+y}{2^{n}}\right)+\frac{1}{2} f\left(\frac{2 x-y}{2^{n}}\right)-2 f\left(\frac{x+y}{2^{n}}\right)\right. \\
& \left.-2 f\left(\frac{x-y}{2^{n}}\right)-12 f\left(\frac{x}{2^{n}}\right)+3 f\left(\frac{y}{2^{n}}\right)\right) \\
\leq & \lim _{n \rightarrow \infty} \frac{16^{n} \theta}{2^{n r}}\left(\|x\|^{r}+\|y\|^{r}\right)=0
\end{aligned}
$$


for all $x, y \in Y$. Hence

$$
\frac{1}{2} Q_{4}(2 x+y)+\frac{1}{2} Q_{4}(2 x-y)=2 Q_{4}(x+y)+2 Q_{4}(x-y)+12 Q_{4}(x)-3 Q_{4}(y)
$$

for all $x, y \in Y$ and so the mapping $Q_{4}: Y \rightarrow X$ is quartic.

Now, let $T: Y \rightarrow X$ be another quartic mapping satisfying (5.2). Then we have

$$
\begin{aligned}
P\left(Q_{4}(x)-T(x)\right) & =P\left(16^{n}\left(Q_{4}\left(\frac{x}{2^{n}}\right)-T\left(\frac{x}{2^{n}}\right)\right)\right) \\
& \leq 16^{n} P\left(Q_{4}\left(\frac{x}{2^{n}}\right)-T\left(\frac{x}{2^{n}}\right)\right) \\
& \leq 16^{n}\left(P\left(Q_{4}\left(\frac{x}{2^{n}}\right)-f\left(\frac{x}{2^{n}}\right)\right)+P\left(T\left(\frac{x}{2^{n}}\right)-f\left(\frac{x}{2^{n}}\right)\right)\right) \\
& \leq \frac{2 \cdot 16^{n}}{\left(2^{r}-16\right) 2^{n r}} \theta\|x\|^{r},
\end{aligned}
$$

which tends to zero as $n \rightarrow \infty$ for all $x \in Y$. So we can conclude that $Q_{4}(x)=T(x)$ for all $x \in Y$. This proves the uniqueness of $Q_{4}$. Thus the mapping $Q_{4}: Y \rightarrow X$ is a unique quartic mapping satisfying (5.2).

Theorem 5.2 Let $r$ be a positive real number with $r<4$, and let $f: X \rightarrow Y$ be a mapping satisfying $f(0)=0$ and

$$
\begin{aligned}
& \left\|\frac{1}{2} f(2 x+y)+\frac{1}{2} f(2 x-y)-2 f(x+y)-2 f(x-y)-12 f(x)+3 f(y)\right\| \\
& \quad \leq P(x)^{r}+P(y)^{r}
\end{aligned}
$$

for all $x, y \in X$. Then there exists a unique quartic mapping $Q_{4}: X \rightarrow Y$ such that

$$
\left\|f(x)-Q_{4}(x)\right\| \leq \frac{1}{16-2^{r}} P(x)^{r}
$$

for all $x \in X$.

Proof Letting $y=0$ in (5.4), we get

$$
\|16 f(x)-f(2 x)\| \leq P(x)^{r}
$$

and so

$$
\left\|f(x)-\frac{1}{16} f(2 x)\right\| \leq \frac{1}{16} P(x)^{r}
$$

for all $x \in X$. Hence

$$
\left\|\frac{1}{16^{l}} f\left(2^{l} x\right)-\frac{1}{16^{m}} f\left(2^{m} x\right)\right\| \leq \sum_{j=l}^{m-1}\left\|\frac{1}{16^{j}} f\left(2^{j} x\right)-\frac{1}{16^{j+1}} f\left(2^{j+1} x\right)\right\| \leq \frac{1}{16} \sum_{j=l}^{m-1} \frac{2^{r j}}{16^{j}} P(x)^{r}
$$


for all nonnegative integers $m$ and $l$ with $m>l$ and all $x \in X$. It follows from (5.6) that the sequence $\left\{\frac{1}{16^{n}} f\left(2^{n} x\right)\right\}$ is a Cauchy sequence for all $x \in X$. Since $Y$ is complete, the sequence $\left\{\frac{1}{16^{n}} f\left(2^{n} x\right)\right\}$ converges. So one can define the mapping $Q_{4}: X \rightarrow Y$ by

$$
Q_{4}(x):=\lim _{n \rightarrow \infty} \frac{1}{16^{n}} f\left(2^{n} x\right)
$$

for all $x \in X$. Moreover, letting $l=0$ and passing the limit $m \rightarrow \infty$ in (5.6), we get (5.5).

It follows from (5.4) that

$$
\begin{aligned}
& \| \frac{1}{2} Q_{4}(2 x+y)+\frac{1}{2} Q_{4}(2 x-y)-2 Q_{4}(x+y)-2 Q_{4}(x-y)-12 Q_{4}(x)+3 Q_{4}(y) \| \\
&=\lim _{n \rightarrow \infty} \frac{1}{16^{n}} \| \frac{1}{2} f\left(2^{n}(2 x+y)\right)+\frac{1}{2} f\left(2^{n}(2 x-y)\right)-2 f\left(2^{n}(x+y)\right) \\
& \quad-2 f\left(2^{n}(x-y)\right)-12 f\left(2^{n} x\right)+3 f\left(2^{n} y\right) \| \\
& \leq \lim _{n \rightarrow \infty} \frac{2^{n r}}{16^{n}}\left(P(x)^{r}+P(y)^{r}\right)=0
\end{aligned}
$$

for all $x, y \in X$. Thus

$$
\frac{1}{2} Q_{4}(2 x+y)+\frac{1}{2} Q_{4}(2 x-y)=2 Q_{4}(x+y)+2 Q_{4}(x-y)+12 Q_{4}(x)-3 Q_{4}(y)
$$

for all $x, y \in X$ and so the mapping $Q_{4}: X \rightarrow Y$ is quartic.

Now, let $T: X \rightarrow Y$ be another quartic mapping satisfying (5.5). Then we have

$$
\begin{aligned}
\left\|Q_{4}(x)-T(x)\right\| & =\frac{1}{16^{n}}\left\|Q_{4}\left(2^{n} x\right)-T\left(2^{n} x\right)\right\| \\
& \leq \frac{1}{16^{n}}\left(\left\|Q_{4}\left(2^{n} x\right)-f\left(2^{n} x\right)\right\|+\left\|T\left(2^{n} x\right)-f\left(2^{n} x\right)\right\|\right) \\
& \leq \frac{2 \cdot 2^{n r}}{\left(16-2^{r}\right) 16^{n}} P(x)^{r},
\end{aligned}
$$

which tends to zero as $n \rightarrow \infty$ for all $x \in X$. So we can conclude that $Q_{4}(x)=T(x)$ for all $x \in X$. This proves the uniqueness of $Q_{4}$. Thus the mapping $Q_{4}: X \rightarrow Y$ is a unique quartic mapping satisfying (5.5).

\section{Competing interests}

The authors declare that they have no competing interests.

\section{Authors' contributions}

All authors conceived of the study, participated in its design and coordination, drafted the manuscript, participated in the sequence alignment, and read and approved the final manuscript.

\section{Author details}

${ }^{1}$ Research Institute for Natural Sciences, Hanyang University, Seoul, 133-791, Korea. ${ }^{2}$ Department of Mathematics, University of Seoul, Seoul, 130-743, Korea.

\section{Acknowledgements}

C. Park was supported by Basic Science Research Program through the National Research Foundation of Korea funded by the Ministry of Education, Science and Technology (NRF-2012R1A1A2004299). D. Y. Shin was supported by Basic Science 
Research Program through the National Research Foundation of Korea funded by the Ministry of Education, Science and Technology (NRF-2010-0021792).

Received: 27 May 2012 Accepted: 5 July 2012 Published: 23 July 2012

\section{References}

1. Fast, H: Sur la convergence statistique. Colloq. Math. 2, 241-244 (1951)

2. Steinhaus, H: Sur la convergence ordinaire et la convergence asymptotique. Colloq. Math. 2, 34-73 (1951)

3. Fridy, JA: On statistical convergence. Analysis 5, 301-313 (1985)

4. Karakus, S: Statistical convergence on probabilistic normed spaces. Math. Commun. 12, 11-23 (2007)

5. Mursaleen, M: $\lambda$-statistical convergence. Math. Slovaca 50, 111-115 (2000)

6. Mursaleen, M, Mohiuddine, SA: On lacunary statistical convergence with respect to the intuitionistic fuzzy normed space. J. Comput. Appl. Math. 233, 142-149 (2009)

7. Šalát, T: On the statistically convergent sequences of real numbers. Math. Slovaca 30, 139-150 (1980)

8. Kolk, E: The statistical convergence in Banach spaces. Tartu ülik. Toim. 928, 41-52 (1991)

9. Wilansky, A: Modern Methods in Topological Vector Space. McGraw-Hill, New York (1978)

10. Ulam, SM: A Collection of the Mathematical Problems. Interscience, New York (1960)

11. Hyers, DH: On the stability of the linear functional equation. Proc. Natl. Acad. Sci. USA 27, 222-224 (1941)

12. Aoki, T: On the stability of the linear transformation in Banach spaces. J. Math. Soc. Jpn. 2, $64-66$ (1950)

13. Rassias, TM: On the stability of the linear mapping in Banach spaces. Proc. Am. Math. Soc. 72, 297-300 (1978)

14. Găvruta, P: A generalization of the Hyers-Ulam-Rassias stability of approximately additive mappings. J. Math. Anal. Appl. 184, 431-436 (1994)

15. Rassias, TM: Problem 16; 2. Report of the 27th international symposium on functional equations. Aequ. Math. 39 , 292-293 (1990)

16. Gajda, Z: On stability of additive mappings. Int. J. Math. Math. Sci. 14, 431-434 (1991)

17. Rassias, TM, Šemrl, P: On the behaviour of mappings which do not satisfy Hyers-Ulam stability. Proc. Am. Math. Soc. 114, 989-993 (1992)

18. Czerwik, P: Functional Equations and Inequalities in Several Variables. World Scientific, Singapore (2002)

19. Hyers, DH, Isac, G, Rassias, TM: Stability of Functional Equations in Several Variables. Birkhäuser, Basel (1998)

20. Rassias, JM: On approximation of approximately linear mappings by linear mappings. J. Funct. Anal. 46, 126-130 (1982)

21. Skof, F: Proprietà locali e approssimazione di operatori. Rend. Semin. Mat. Fis. Milano 53, 113-129 (1983)

22. Cholewa, PW: Remarks on the stability of functional equations. Aequ. Math. 27, 76-86 (1984)

23. Czerwik, S: On the stability of the quadratic mapping in normed spaces. Abh. Math. Semin. Univ. Hamb. 62, 59-64 (1992)

24. Aczel, J, Dhombres, J: Functional Equations in Several Variables. Cambridge University Press, Cambridge (1989)

25. Eshaghi Gordji, M, Savadkouhi, MB: Stability of a mixed type cubic-quartic functional equation in non-Archimedean spaces. Appl. Math. Lett. 23, 1198-1202 (2010)

26. Isac, G, Rassias, TM: On the Hyers-Ulam stability of $\psi$-additive mappings. J. Approx. Theory 72, 131-137 (1993)

27. Jun, K, Lee, Y: A generalization of the Hyers-Ulam-Rassias stability of the pexiderized quadratic equations. J. Math. Anal. Appl. 297, 70-86 (2004)

28. Jung, S: Hyers-Ulam-Rassias Stability of Functional Equations in Mathematical Analysis. Hadronic Press, Palm Harbor (2001)

29. Park, C: Homomorphisms between Poisson JC*-algebras. Bull. Braz. Math. Soc. 36, 79-97 (2005)

30. Rassias, JM: Solution of a problem of Ulam. J. Approx. Theory 57, 268-273 (1989)

31. Rassias, TM: Functional Equations and Inequalities. Kluwer Academic, Dordrecht (2000)

32. Rassias, TM: On the stability of functional equations in Banach spaces. J. Math. Anal. Appl. 251, 264-284 (2000)

33. Rassias, TM: On the stability of functional equations and a problem of Ulam. Acta Appl. Math. 62, 23-130 (2000)

34. Jun, K, Kim, H: The generalized Hyers-Ulam-Rassias stability of a cubic functional equation. J. Math. Anal. Appl. 274, 867-878 (2002)

35. Lee, S, Im, S, Hwang, I: Quartic functional equations. J. Math. Anal. Appl. 307, 387-394 (2005)

doi:10.1186/1687-1847-2012-123

Cite this article as: Park and Shin: Functional equations in paranormed spaces. Advances in Difference Equations 2012 2012:123.

\section{Submit your manuscript to a SpringerOpen ${ }^{\circ}$ journal and benefit from:}

- Convenient online submission

Rigorous peer review

- Immediate publication on acceptance

- Open access: articles freely available online

- High visibility within the field

- Retaining the copyright to your article 